\title{
Belief-like Imaginings and Perceptual (Non-)Assertoricity
}

\author{
Alon Chasid and Assaf Weksler
}

Forthcoming in Philosophical Psychology

\begin{abstract}
A commonly-discussed feature of perceptual experience is that it has 'assertoric' or 'phenomenal' force. We will start by discussing various descriptions of the assertoricity of perceptual experience. We will then adopt a minimal characterization of assertoricity: a perceptual experience has assertoric force just in case it inclines the perceiver to believe its content. Adducing cases that show that visual experience is not always assertoric, we will argue that what renders these visual experiences non-assertoric is that they are penetrated by belief-like imaginings. Lastly, we will explain why it is that when belief-like imaginings - as opposed to beliefs (and other cognitive states) — penetrate visual experience, they render visual experiences non-assertoric.
\end{abstract}

\section{Perceptual Assertoricity}

Perceptual experiences are usually claimed to have 'assertoric' or 'phenomenal' force. One way to elucidate this feature is to say that perceptual experience purports to reveal what the world is like, that is, to inform us about the world. Siegel and Silins (2015), e.g., claim that: 
There seems to be an aspect of the phenomenal character of perceptual experience that is distinct from the phenomenal character of imagery, episodes of wondering, and pangs of desire. ... Our perceptual experience [of a black dot] purports to reveal how the world is, whereas visualizing the dot, wondering whether there is such a black dot in front of you, or feeling a pang of desire for a black dot does not. Phenomenal force is analogous to assertoric force, in its role for the speaker. Making an assertion is a way to express how you believe things to be. Similarly, perceptual experience is a way to take in how things seem to you to be. Phenomenal force is analogous to assertoric force to the extent that both attach to belieflike states. (790-1)

Similarly, Matthen (2005) maintains that "visual states produced by looking have an implied assertion operator - they convey to us an act of sensory classification performed by the visual system on an object that is present" (306). The idea is that the visual experience of, say, a red tomato, has the intrinsic phenomenal property of 'asserting' that there is a red tomato in front of the perceiver. Other mental states, e.g., desires, imaginings, speculations, etc., are non-assertoric: they do not purport to inform us — at least not directly — about the world; they have no "implied assertion operator.”

Although the assertoricity of perceptual experience is deemed to be phenomenal, it should not be confused with the sensory phenomenology of experience (i.e., the phenomenological aspects of perceptual experience that, on representationalist views of perception, supervene on experience's representational content). Assertoricity is taken to be constitutive of perceptual experience, but not to follow from, or be intrinsically related to, its sensory aspects. The phenomenality of perceptual assertoricity is commonly described in psychological terms: 
perceptual experiences are described as accompanied by 'feelings of assurance' that they represent the world faithfully, as having 'the feel of truth,' as 'forcing themselves upon us as being true,' etc. (see Teng 2018, 641ff).

Perceptual assertoricity is invoked in at least two philosophical contexts. One context is that of representationalist or doxastic views of perception. Such views often maintain that experiences not only have representational content, but also 'assert' that their content is true, just as beliefs 'assert' that their content is true. Martin (2002, 386-7), for instance, distinguishes between two kinds of mental representation, stative and semantic. Stative representation is a narrow category, encompassing only representations that 'state' that their content is true: beliefs, judgments, and —on representationalist accounts of perception—perceptual experiences. Semantic representation is broader, also covering mental representations that do not 'state' that their content is true: desires, hopes, speculations, etc.

Gluer (2009, 306ff) too distinguishes two kinds of mental representations: strong and weak. Both have representational content, but only strong representations have assertoric force, i.e., represent the world as being such as to render this content true. Gluer notes that assertoricity ensues from a representational state's having a mind-to-world direction of fit. On Gluer's view, perceptual experiences, which—like beliefs and judgments—-have this direction of fit, are strong representations. Weak representations, by contrast, have either a world-to-mind direction of fit (e.g., desires), or the "null direction of fit" (e.g., imaginings and speculations), and hence lack assertoric force (2009, note 16$)$.

A related context in which perceptual assertoricity is invoked is that of the justificatory status of perceptual experience. 'Dogmatists' contend that a perceptual experience with content $p$ provides an immediate, i.e., non-inferential, justification for believing that $p$. The tenability of 
immediate justification is sometimes explained by the fact that perceptual experience has assertoric or phenomenal force. Teng (2018) notes that dogmatists ascribe phenomenal force to perceptual experience, but not beliefs and judgments, since the latter do not provide immediate justification. Siegel and Silins (2015) similarly explain that for dogmatists, the "phenomenal force of experiences make[s] them belief-like enough to justify [beliefs] because they assertively represent propositions, but they are not belief-like enough to require justification themselves" (792).

The questions of whether the assertoric force of perceptual experiences establishes the tenability of non-inferential justification, and whether this force is like the assertoric force of beliefs, are not relevant to our argument. This paper adopts a minimal characterization of perceptual assertoricity, taking it to be the property of inclining the perceiver to believe what her experience says about the world. This characterization is consistent with the aforementioned psychological characterizations of assertoricity ('feeling of assurance,' etc.). We will likewise assume that an assertoric experience induces the perceiving subject to invoke it in justifying her beliefs, whether or not that justification is immediate. ${ }^{1}$ Those who maintain that perceptual experience does not provide immediate justification should be willing to accept the minimal characterization of perceptual assertoricity as the property of inclining the perceiver to believe the content of her experience. Note that our assumption is not that perceptual assertoricity is a

\footnotetext{
${ }^{1}$ An anonymous referee noted that as infants and non-human animals do not engage in reasoning and justifying, they cannot be induced by perceptual experience to invoke that experience in justifying beliefs. We accept this claim. The inclination in question manifests itself in reasoning and justifying only in subjects who can carry out these acts; in infants, etc., it seems that, as long as the experience persists, the inclination directly generates a belief with the experienced content.
} 
contingent causal relation between perceptual experience and belief: rather, the inclination in question is assumed to be constitutive of perceptual experience, reflecting the role of perceptual experience in revealing what the world is like.

Like any characterization of perceptual assertoricity, our characterization is compatible with the fact that a perceiver, despite being inclined to believe the content of her experience, may wind up not believing it. Having evidence against the content of her experience, she may resist the inclination, and not believe that content. Can strong defeating evidence alone thwart the purported inclination to believe? We address this question below.

This paper argues that although perceptual experience is assertoric in many cases, it is not always assertoric: sometimes we are not inclined by a perceptual experience to believe what it says about the world, and do not take it to justify that belief.

One further note is in order. Although our argument can be adapted to fit any theory of perception (specifically, various forms of disjunctivism and naïve realism), for convenience it will be formulated in representationalist terms. We will assume that visual experiences are representational states, i.e., that they have content, the form of which is propositional.

Experiences are thus either veridical or non-veridical by virtue of satisfying or failing to satisfy correctness conditions. (Disparities between different versions of these representationalist assumptions are unimportant here).

\section{Non-Assertoric Experiences}

Consider the following cases: 
Case A: Mary perceives a distant object as looking like a wheel lying on the ground: her visual experience represents the object as circular and slanted (experience A1). Recalling, from past experience, that the distant object is not a wheel, but a standing elliptical boulder, Mary's experience adjusts, and represents the object correctly, namely, as an elliptical boulder (experience A2). Toying with the idea that the elliptical boulder looks like an abandoned wheel, Mary reverts to the non-veridical experience of a circular wheel (experience A3).

We will initially claim (though we will soon refine this claim) that whereas A1, and, obviously, $\mathrm{A} 2$, are assertoric, A3, despite being identical to A1 in content and sensory phenomenology, is non-assertoric: it does not generate an inclination to believe its content.

Case B: looking in the mirror, John visually experiences a spot on his nose (experience B1). Moving his head, John's visual experience shifts, representing the spot as being on the mirror, not on his nose (experience B2). Yet amused by the fact that the spot looked like it was on his nose, John moves his head back, so as to revert to the non-veridical visual experience of the spot as being on his nose (experience B3).

Here too, we will initially claim that whereas B3 is identical to B1 in sensory phenomenology and content, it is non-assertoric: it does not incline John to believe its content; a refined version of this claim will be endorsed below.

Similar cases abound. E.g., knowing that she is looking at a shaded white object, Mary may nevertheless deliberately 'shift' from experiencing a shaded white object to experiencing a grey 
object. Under certain conditions, the latter experience will be non-assertoric: Mary will not be inclined to believe that the object is grey. Looking in the mirror, John can pretend that he is observing his doppelgänger, and have an experience with different content (e.g., different objects, left-right relations, etc.); this experience, too, will be non-assertoric. Further cases of perceptual non-assertoricity will be adduced below. A specific type of non-assertoric experiences, including experiences we sometimes have in watching 'visual fictions'-plays, movies, etc.-will be analyzed in the next section. We will argue that experiences like A3 and B3 are non-assertoric for the same reason the 'visual fiction' experiences are non-assertoric. For convenience, we will focus on case B, but our discussion also applies to case A and other garden-variety examples of non-assertoricity.

Despite the temporal discontinuity between B1 and B3 (A1 and A3, etc.), these experiences are identical in important respects: not only are the sensory phenomenology and representational content of these experiences identical, but the perspectives, viewing conditions, and sensory stimuli associated with B1 and B3 are also identical. The crucial difference between the initial experience and the 'reverted-to' experience pertains to assertoricity: B1 generates an inclination to believe its content, whereas B3 does not. Since there is no 'external' explanation of this difference (given that the perspectives, viewing conditions, etc., are identical), to account for the non-assertoricity of B3, reference must be made to an 'internal' influence. B3's nonassertoricity, we will argue, arises from its penetration by belief-like imaginings.

It might be claimed that, contra our contention, B3 is assertoric. Why not say that B3 inclines John to believe that the spot is on his nose? It might be argued that though we are free to stipulate that in reverting to experiencing the spot as being on his nose, John's intention is to pretend or to amuse himself - this is, indeed, how we described the case - nevertheless, once 
John has B3, he is inclined, despite his intention to pretend, be amused, etc., to believe that the spot is on his nose. For in principle, every perceptual experience is assertoric.

This objection raises the more general question of how the putative inclination to believe manifests itself. A plausible answer is that it manifests itself in the subject's mental acts, specifically, her engaging in reasoning and justifying her beliefs. That is, if perceptual experience generates an inclination to believe, that experience must play some justificatory role (assuming that the subject is capable of reasoning and justification; see note 1). Even when, due to defeating evidence, the subject does not end up believing the content of her experience, while she is having the experience, the inclination to believe reveals itself in the subject's doubts regarding the objects she is looking at. In other words, the inclination generates epistemic 'tension' between an experience and one's beliefs about the experienced objects.

We do not deny that such tension between beliefs and experiences sometimes arises. Our claim is that it does not arise in the case of John's spot, and hence, given that the inclination in question manifests itself epistemically, B3 is non-assertoric. More precisely, John does not examine whether B3 is veridical, and does not consciously consider it in reasoning about what the world is like; he is just amused by B3. To see the difference between B3 and experiences that generate epistemic tension, compare B3 to experiencing visual illusions such as the Muller-Lyer illusion, Shepard's tables, trompe-l'oeil, etc. Even someone who is familiar with the Muller-Lyer illusion, and concerned about correctly judging whether the lines are equally long, will be inclined to believe the content of her experience, i.e., to believe that the lines aren't equal. This inclination manifests itself in doubt about whether the lines are indeed equal. Familiarity with the illusion doesn't suffice to alleviate the doubt: the viewer may keep scrutinizing the lines, 
wondering whether she has focused sufficiently on the intersections between the lines and the arrows, whether the lines were drawn accurately, etc.

To further clarify this, let us adduce a different sort of example. Suppose that, having robust evidence that her honorable friend Jim is abroad, Maggie visually experiences someone who looks very much like Jim stealing a book from the library. ${ }^{2}$ Maggie might respond to her experience in two different ways. On one scenario, her visual experience generates epistemic tension: despite having evidence that Jim is honorable, that he is abroad, etc., Maggie keeps wondering whether the thief she sees is Jim, whether she is wrong to believe that Jim is honorable, etc. Maggie may continue to believe that Jim is not the thief, but be unable to shake off the doubt generated by her experience. On this scenario, Maggie's experience is assertoric: despite the defeating evidence, her experience inclines her to believe that Jim is the thief.

On the second scenario, Maggie's experience does not generate epistemic tension. Having the same evidence to the effect that Jim is honorable, that he is abroad, and so on, Maggie is merely amused by her experience, pretending that she observes Jim stealing a book. Believing that the thief is not Jim, she might likewise engage in counterfactual speculation, in response to this experience, about how bizarre it would be to see Jim stealing a book. Maggie's experience, on this scenario, raises no doubts about Jim's (real-world) character. She does not believe, nor is

\footnotetext{
${ }^{2}$ On views according to which singular objects are represented in perceptual experience, and represented objects are determined 'internally' (see, e.g., Siegel 2010, 5-6), Maggie experiences Jim. On other views, Maggie experiences a set of properties associated with recognizing Jim. Regardless of whether perceptual content is taken to be singular, this example illustrates the difference between cases where the visual experience generates epistemic tension, and cases where it doesn't.
} 
she inclined to believe, that the thief is Jim: there is no tension between her experience and her beliefs.

Like Maggie's second-scenario experience, there is no tension between B3 and John's belief that he does not have a spot on his nose. In this respect, B3 differs from Maggie's first-scenario experience, as well as from visual experiences arising from visual illusions such as trompe-l'oeil. John is only toying with the idea that he has a spot on his nose, enjoying his act of pretense. He may speculate about whether — in a world in which he has a spot on his nose- - his career as a newscaster would be affected. But he experiences no epistemic tension. This is also true of the other non-assertoric experiences mentioned above. A subject who pretends, while looking in the mirror, that she is looking at her doppelgänger, may experience a different object, different leftright relations, etc. Usually, this experience will not generate any tension with her belief that there isn't really a doppelgänger there. She will mainly be amused by her experience, without being inclined to believe its content.

Note further that, with respect to assertoricity, B3 (as well as the other non-assertoric experiences) is similar to mental images conjured up in visualizing. That is, although the nonassertoric experiences in question may be triggered by external stimuli, their relevance (or lack thereof) to reasoning about what the objects being viewed are really like is similar to the relevance of mental imagery that arises in visualizations to reasoning about the real-world objects being viewed. In this context, it is edifying to invoke Perky effects. In the experiment described in Perky (1910), participants looked at an image of, say, a banana, projected onto a screen, but believed - in light of their intention to visualize a banana, in line with the instructions they had received - that they were only visualizing a banana. The participants reported that they were merely visualizing, and denied that they were perceptually experiencing anything. This 
experiment is often interpreted as showing that the participants' (veridical) visual experience was non-assertoric: it did not incline them to believe that there was something yellow in front of them, allegedly because they believed that they were only visualizing a banana (Ghijsen 2014, 1557ff; Siegel and Silins 2015, 791; Teng 2018, 644ff). Although the structure of B3 differs from the structure of the (veridical) Perky perceptual experiences, these experiences demonstrate that under certain conditions, the inclination to believe the content of an experience can be thwarted, and there is no epistemic tension between experience and belief. These conditions, we will argue, include the penetration of perceptual experiences by belief-like imaginings, which also explains why the Perky experiences are non-assertoric.

If B3 does not generate epistemic tension, it is difficult to see in what sense it is assertoric, as the objection under discussion contends. This objection may be premised on the assumption that defeating evidence cannot block perceptual assertoricity, and hence B3 cannot be rendered non-assertoric solely by John's having robust evidence against it. We are willing to accept this assumption: we do not claim that having evidence against the content of a perceptual experience thwarts the inclination to believe that content. As demonstrated by the aforementioned visual illusions, the 'Jim-like book thief' experience (on the first scenario), and similar cases, perceptual experience can incline one to believe its content, even if one has robust evidence against that content. What can thwart assertoricity, we argue, is engaging in imagining. It is therefore important to bear in mind that the experiences we describe as non-assertoric do not arise, or do not only arise, when the subject has defeating evidence; they arise in the context of pretending, amusing oneself, pondering counterfactuals, etc.

A different objection to our claim that B3 is non-assertoric denies that the inclination in question manifests itself epistemically or consciously. Though John does not (consciously) 
occupy himself with examining whether B3 is veridical, and is merely amused by it, he may nonetheless have some slight, perhaps non-conscious, inclination to believe that he has a spot on his nose - an inclination too slight to make him ponder whether there really is a spot on his nose. On this objection, while we are free to stipulate that, in pretending that he observes a spot on his nose, John does not consciously invoke B3 to justify a belief regarding the presence of a spot on his nose, it cannot be the case that B3 does not incline him in the slightest to believe that there is a spot on his nose; it must incline him, at least minimally, to hold that belief. Moreover, it seems plausible that the purported inclination to believe is a gradational property rather than a binary one. If the inclination to believe has gradations, then instead of describing B3 as fully nonassertoric, B3 should be described, according to this objection, as generating a low degree of inclination to believe - a degree too slight to engender conscious epistemic tension.

This objection is somewhat problematic, as it doesn't provide a criterion that can determine whether a perceptual experience inclines one, to any degree, to believe its content. What feature, for instance, can determine that the participants in Perky's experiment were not inclined by their (veridical) experiences, non-consciously or to a slight degree, to believe that there was a real yellow image in front of them? Why not say that visualizations in general incline one to believe their content? How can such conjectures be refuted, if we deny that the inclination in question manifests itself epistemically? Arguing that perceptual experience is always assertoric to some degree, and therefore that B3, the doppelgänger-in-the-mirror experience, the Perky experiences, etc., generate some inclination to believe, seems like begging the question.

Nevertheless. to address the second objection, let us suppose that there is such a criterion, or there is other reason to maintain that inclinations to believe can arise without being manifested in conscious epistemic tensions. Adapting our argument to accord with the assumption that the 
inclination to believe is a matter of degree, we can refine our claim and assume that B3 generates a minimal or non-conscious inclination to believe. Despite these moves, however, the main question stands, since the fact that B3's assertoricity is slight remains in need of explanation. For in other cases, as we showed, a subject may be strongly inclined, despite having defeating evidence, to believe what her experience tells her. Why is it the case that in some instances we are strongly inclined to believe the content of our perceptual experience, and in other instances, we are only slightly inclined to believe it? What explains the difference? We propose that, at least in the cases in question, the explanatory factor is belief-like imagining: penetration by belief-like imaginings may reduce, if not completely block, an experience's assertoric force.

\section{Imaginative Penetration}

Our proposed explanation highlights the fact that, in the cases in question, the subjects engage in some kind of pretending or make-believe. John, for instance, engaged in imaginings to the effect that he experienced the spot as being on his nose. This proposed explanation is based on Walton's account of visual fictions (Walton 1990, ch. 8; 2008, chs. 7-9), which invokes imaginative penetration to account for the (non-veridical) perceptual experiences one ordinarily has in watching plays, looking at pictures, etc. Our claim is that Walton's thesis that imaginings can penetrate perceptual experience explains perceptual non-assertoricity.

The imaginings our explanation invokes, as per Walton's theory, are propositional, 'attitudinal' imaginings. They usually arise in reading or watching works of fiction, playing games of make-believe, daydreaming, etc. They may also be conjured up, spontaneously or deliberatively, without any connection to these contexts: we may simply intend to imagine, or 
find ourselves imagining, various propositions. Setting aside divergences between different accounts of propositional imaginings, it is widely accepted that these imaginings are belief-like in that they are related to other kinds of mental states (e.g., conative or desire-like states, emotional responses, motivations, etc.) in a manner akin to that in which beliefs are related to those, or similar, states. ${ }^{3}$ For instance, a child pretending that the neighbor across the street is a monster may, when she sees the neighbor approaching, imagine that a monster is approaching, and thus may have a fear-like emotion, or be in a desire-like state, 'wishing' that the monster would go away, etc. Our claim is that propositional imaginings also resemble beliefs in being able to penetrate perceptual experience.

Although propositional, belief-like imaginings may be accompanied by mental images (sometimes called 'sensory' or 'imagistic' imaginings), they should not be identified with such images. Some argue that belief-like imaginings and mental images need not arise together. Walton (1990, 13), e.g., maintains that "imagining can occur without imagery"; Van Leeuwen $(2013,222)$ similarly claims that “attitude imaginings needn't have an imagistic representational format": e.g., imagining that elves live forever has no imagistic structure. ${ }^{4}$ Even those who hold that imaginings must have an imagistic component (e.g., Peacocke 1985; Kind 2001) accept that the content of propositional imaginings is not fully determined by images.

\footnotetext{
${ }^{3}$ That attitudinal imaginings function like beliefs in certain respects, and differ from mental images, is widely accepted in the literature on imaginings. See, e.g., Currie and Ravenscroft (2002), Doggett and Egan (2007; 2012), Gendler (2003; 2013), Kind (2013; 2016), LanglandHassan (2012), Liao and Doggett (2014), Nichols (2004; 2006a; 2006b), Nichols and Stich (2003), Schellenberg (2013), Van Leeuwen (2011), Walton (1990; 2008; 2015).

${ }^{4}$ See also Kind (2016, 5-7); Schellenberg $(2013,499)$.
} 
Whatever the relation between mental images and belief-like imaginings, we will invoke the latter to explain non-assertoricity. It is doubtful whether mental imagery can account for perceptual non-assertoricity, since mental images also arise in assertoric contexts, e.g., in recollection, ${ }^{5}$ and hence do not, in themselves, seem capable of blocking perceptual assertoricity. As will be explained in $\S 4$, attitudinal, belief-like imaginings are, by contrast, able to block assertoricity. We will also argue that when mental images arise in the context of non-assertoric experience, the non-assertoricity does not ensue from these images, but from belief-like imaginings that accompany them.

Cognitive states are claimed to penetrate perceptual experience in various ways (see, e.g., Siegel and Silins 2015, 803ff; Deroy 2015, 765ff). We will assume that cognitive penetration occurs, without discussing specific modes and mechanisms of penetration. Focusing on the penetration of perceptual experience by propositional, belief-like imaginings, we contend that just as beliefs can penetrate perceptual experience, so too belief-like imaginings, to a great extent, can penetrate perceptual experience. But for reasons explained in $\S 4$, in the case of imaginative penetration, the penetrated experience is rendered non-assertoric.

Consider a relatively simple example of belief-penetration adduced by Siegel $(2012,202)$. Jill believes that Jack is angry at her, and this belief generates a visual experience of Jack as being angry. In this case, a belief penetrates an experience to the effect that the experience has content that reflects the content of the penetrating belief. Suppose, however, that Jill does not believe that Jack is angry at her, but decides to imagine that Jack is angry at her. We maintain that this imagining can also penetrate Jill's visual experience to the effect that it represents Jack

\footnotetext{
${ }^{5}$ See also Van Leeuwen (2013, 222). Similarly, Macpherson (2012) adduces examples of assertoric perceptual experiences that she claims are penetrated by mental images.
} 
as being angry. In this case, Jill veridically and assertorically visually experiences Jack's face as having certain properties, and also believes that it has those properties. But Jill does not believe, nor is she inclined to believe, that Jack is angry: she imagines that Jack is angry, and consequently, visually experiences him, non-veridically and non-assertorically, as being angry. Her imagining, we argue, functions just as the belief that Jack is angry functions in Siegel's example; it prompts a top-down modulation of her experience, to the effect that Jill experiences Jack as being angry. Being penetrated by her imagining, Jill's experience of Jack as angry is part of an imaginative trip, and hence, non-assertoric.

In his account of visual fictions, Walton defends the thesis that propositional imaginings can penetrate perceptual experience (1990; 2008). To see how Walton's idea can account for nonassertoricity, we will focus on the sort of experiences he tries to explain. Consider the following case:

Case C: Watching a play, Anna, by virtue of having certain visual experiences, imagines the play's content. Some of her perceptual experiences are veridical, e.g., she experiences people walking, hears them talking, etc. Some, however, are non-veridical, e.g., she experiences people as being angry, she experiences the firing of a gun, someone bleeding, a couple embracing as the sun sets over the sea behind them.

Anna's non-veridical perceptual experiences are, to a great extent, non-assertoric: Anna is hardly inclined to believe that the people on the stage are really angry, that a (real) gun was fired, that the pooling red liquid is blood, that the colorful backdrop is a sunset. Certain (non-veridical) experiences may, perhaps, incline Anna, to some degree, to believe their content: she may 
occasionally be inclined to believe that one actor is indeed angry at another actor, or, in light of remarkable special effects, that the backdrop of breaking waves is not cardboard scenery, but actual water. But such inclinations are not generated by every non-veridical experience Anna has in watching the play. Were Anna inclined to believe the content of her experiences, as she is inclined to believe the content of similar experiences in non-fictional contexts, her overall doxastic state would be completely different. Compare Anna's doxastic state to that of a spectator who, utterly immersed in the play, starts to worry that the people on stage are livid, a real gun was fired, the victim is actually bleeding, etc. Experiencing the same content that Anna experiences, this spectator repeatedly suspects that something bad is happening on stage, and is disposed to act accordingly (to scream, seek help, call 911, etc.). Anna, by contrast, is enjoying the play, and to a great extent, disinclined to believe the content of her non-veridical experiences. ${ }^{6}$

What renders Anna's non-veridical experiences non-assertoric? What distinguishes between, say, her assertoric (veridical) experience of someone's face, and her non-assertoric (nonveridical) experience of someone's being angry? The answer seems to pivot on the fact that Anna's experiences arise in the context of watching a play and imagining the play's content. But how, exactly, do her imaginings impact her experiences?

\footnotetext{
${ }^{6}$ Anna may well be moved by the play, just as anyone who reads a work of fiction may be moved by the imaginings aroused by engagement with that work. However, emotional responses to works of fiction are generally explained by the fact that one imagines their content (see the references in note 3). To our knowledge, nowhere in the literature is it argued that emotional responses to fiction are generated by an inclination to believe the fictional content.
} 
Walton's account addresses the last question. It argues that the (non-veridical) perceptual experiences we ordinarily have in watching movies, looking at pictures, etc., are penetrated by propositional imaginings just as ordinary perceptual experiences are penetrated by beliefs. Regarding the visual experiences we ordinarily have in looking at a picture, Walton maintains that "cognitive states of many sorts—-beliefs, thoughts ... —enter into our perceptual experiences"; in particular, "imaginings ... enter into visual experiences. ... The imaginings called for when one looks at a picture inform the experience of looking at it" (Walton 1990, 295ff). ${ }^{7}$ Walton's account of visual fictions is more complicated than his general account of fiction. Walton argues that works of fiction serve as props in a game of make-believe: a work counts as fiction just in case it mandates its audience to imagine its content (Walton 1990, 72ff). In reading a novel, for instance, we first grasp its content-what it asks us to imagine - then respond by imagining that content. When engaging with visual fictions (or more broadly, "depictive representations"; 1990, ch. 8), however, we do not first visually experience all the content that we are mandated to imagine at a given moment in the play, and then imagine it. Rather, Walton argues, in such cases, some imaginings arise before the pertinent visual experiences, imparting them with new content.

\footnotetext{
${ }^{7}$ For further comparison of belief-penetration and imaginative-penetration, see Walton (2008, 138ff). Walton uses the term "imagining seeing" to describe the overall mental state wherein imaginings penetrate visual experience. Yet he maintains that the state is not imagining, but a visual experience that is colored by one's imaginings: the seeing and the imagining become "a single complex phenomenological whole" $(1990,295)$; see also the analysis of Walton's account in Chasid (2016, 28ff).
} 
As Chasid (2016, 30ff) points out, Walton does not detail which imaginings penetrate, and hence arise prior to, the perceptual experience of objects or events depicted by a visual work of fiction (e.g., the visual experience of a picture's depictum; perceptual experiences of objects, properties, and events depicted by a play), and which imaginings arise after those experiences. This lacuna in Walton's account can be filled in various ways. Perhaps the spectator's expectations or knowledge about the depicted events and objects prompt her to imagine certain propositions (e.g., that someone is angry, that the sun is setting, etc.); these imaginings then penetrate her experience to the effect that she visually experiences those propositions. Or perhaps, in looking at a picture or watching a play, the perceiving subject veridically and assertorically experiences certain combinations of low-level properties (colors, shapes, etc.), and this experience of low-level properties prompts her to imagine that the things she is looking at have certain high-level properties (being a sunset; being angry) — properties that the subject does not believe those things really have. This imagining then penetrates her perceptual experience to the effect that the experience represents those high-level properties. ${ }^{8}$

One way or another, some experiences that arise in watching (looking at) visual fictions, Walton claims, are penetrated by imaginings. We contend, on the basis of Walton's thesis, that

${ }^{8}$ Chasid $(2016, \S 4)$ makes a similar argument, asserting that imaginings can function like beliefs that are associated with recognizing high-level properties. In watching a play or looking at a picture, the spectator believes that she is looking at actors or at a picture's marked surface, but processes these stimuli through imaginings that have the same content as her recognitional beliefs. (Chasid invokes the widely-accepted claim that in general, imaginings can have the same content as beliefs.) I.e., the spectator's experience has the same top-down modulation that experiences have in non-imaginative contexts, except that imaginings replace beliefs. 
Anna's non-veridical experiences are non-assertoric because they are penetrated by imaginings. Not being totally immersed in the performance, Anna visually experiences angry faces, a bleeding victim, a sunset over the sea, etc., without being inclined by these experiences to believe that anyone on stage is angry or bleeding, or that the sun is setting. Returning to A3 and B3, their non-assertoricity can also be accounted for by imaginative penetration. The main difference between Anna's non-veridical experiences and A3 (B3) is that Anna's experiences arise in the context of engaging with fiction, whereas they do not. This difference, however, is superficial. Whether a subject intends to imagine, imagines by following 'instructions,' or imagines spontaneously, her imaginings, we contend, can render her perceptual experience nonassertoric.

When John, e.g., realizes that the spot is on the mirror, he decides to pretend that he observes the spot as being on his nose, and proceeds to imagine that the spot is indeed on his nose. By top-down modulation that incorporates imaginings, John experiences the spot as being on his nose. The same is true of the other garden-variety cases, whether the subject's imaginings arise spontaneously or intentionally. Maggie (on the second scenario) imagines that the person she sees is Jim, hence her experience of Jim's stealing a book does not incline her to believe that Jim is stealing a book. Similarly, when John decides to imagine himself gazing at a doppelgänger (by looking in the mirror), he experiences his doppelgänger non-assertorically. And when Jill imagines (without believing) that Jack is angry at her, a top-down modulation occurs-a modulation structurally similar to the modulation in Siegel's example - to the effect that she experiences Jack as being angry, though this experience doesn't incline her to believe that he really is angry. 
Since belief-like imaginings arise not only in the context of reading or watching fiction, but also in quotidian contexts, intentionally or spontaneously, non-assertoric perceptual experiences can also arise, intentionally or spontaneously, in such contexts. To reiterate, the argument we are making is that, given that beliefs can penetrate perceptual experience, belief-like imaginings can, to a great extent, do so too. Our starting point was the fact that sometimes we are not inclined to believe the content of our perceptual experiences, or are inclined to believe that content only slightly. The slightness or total absence of an inclination to believe cannot be attributed to sensory input, which can be identical in cases where we are inclined to believe the content of perceptual experiences, and cases where we are not. Nor can it be attributed to defeating evidence, which, we showed, is insufficient to thwart the putative inclination to believe the content of perceptual experiences. We have suggested that it be accounted for in terms of imaginative penetration. Due to being penetrated by belief-like imaginings, perceptual experiences that take place in the context of imagining either do not induce the perceiver to believe their content, or induce her to believe that content to a far smaller degree than would similar experiences where no relevant imaginings arise.

\section{Imaginings and Non-Assertoricity}

Why do belief-like imaginings have the power to block or substantially reduce perceptual assertoricity? To answer this question, it is tempting to adduce the fact that imaginings themselves are non-assertoric states: they do not ordinarily incline the imaginer to believe their content. Since imaginings are non-assertoric, the seemingly straightforward answer is that, to the extent that imaginings influence perceptual experience as we described above, they do so by 
neutralizing a perceptual experience's 'implied assertion operator,' so that the experiencer is not inclined to believe what the experience tells her about the world.

This explanation, however, is insufficient, since other kinds of non-assertoric states penetrate perceptual experience without rendering it non-assertoric. Desires, for instance, are non-assertoric states, yet they can penetrate perceptual experience without reducing its assertoricity (see, e.g., Stokes 2012, on hunger and "background desires"). A desire for rain may penetrate one's visual experience to the effect that one has an assertoric experience of rain. But if, as the example of desires shows, the penetrating state's non-assertoricity is not what renders a perceptual experience non-assertoric, what feature do imaginings have that enables them to thwart, or significantly reduce, the putative inclination to believe?

The answer is that imaginings are non-assertoric because they are not 'directed' at the real world; they do not purport to represent that which is true simpliciter (i.e., in the real world), but that which is true in an imaginary world. When Jill, for instance, imagines that Jack is angry at her, she does not take the imagined proposition to be true simpliciter, but to be true in the imaginary world, the world of her imaginative episode. Jill is therefore not inclined by her imagining to believe the proposition that Jack is angry at her, because in imagining that proposition, she is only taking it to be true in an unreal, imaginary world. Our point is that a perceptual experience that is penetrated by imaginings (Jill's visual experience of Jack's being angry) likewise does not generate an inclination to believe its content, since it too is directed at an imaginary world (henceforth: $\mathrm{i}$-world): it is not meant to represent that which is true simpliciter, but that which is true in the world of the imaginative episode.

The idea that imaginings do not pertain to the real world is discussed in Walton $(1990 ; 2015$, ch. 2). Walton characterizes fictional (or imaginary) worlds in terms of works of fiction, 
claiming that they are "sets of propositions-as-indicated-by-a-given-work" (1990, 67). Anna's imaginings (case C), for instance, pertain to the play's world — the set of propositions depicted by the play. Imaginative episodes can, of course, arise not only in response to reading or watching works of fiction, but also in daydreaming, pretending, playing games of make-believe, etc. In such cases, the i-world is identified with the set of propositions assumed to be true by the subject, intentionally or spontaneously, when she engages in imagining. In the world of Jill's imaginative episode, e.g., it is true that Jack is angry at her. Imaginary worlds are relatively indeterminate: the world of Jill's imaginative episode, e.g., may be comprised of very few propositions, one of which is that Jack is angry at her. (Henceforth we use the general term 'imaginary world' ('i-world') rather than the term 'fictional world,' since the latter term is often reserved for contexts involving responses to works of fiction).

It should be noted that i-worlds may incorporate propositions that are true simpliciter, and propositions that refer to real objects: in the world of Jill's imaginings, it is (the real) Jack who is angry, and both Jill and Jack have some of their real-world properties. Yet given that in the iworld, Jack is angry at Jill, this world differs from the real world, being constituted by different truths. When, by way of imagining, the proposition that Jack is angry at Jill is accepted as true, this imagining penetrates Jill's visual experience to the effect that her experience represents Jack as being angry. Her experience, like the imagining that has penetrated it, reflects what is true in the i-world, and hence does not incline Jill to believe that Jack is really angry at her.

This applies to B3 and the other garden-variety imaginings discussed above. John's imagining that he has a spot on his nose purports to represent what is true in an i-world. B3 thus pertains to that world: it does not reflect truth simpliciter, hence it does not incline John to believe that he has a spot on his nose. A3, the doppelgänger experience, the 'Jim-like book thief' 
experience (construed as per the second scenario), and similar experiences are explained the same way. Being shaped by imaginings, imaginatively-penetrated experiences do not purport to inform the perceiving subject about the real world, and therefore do not incline her to believe their content. In this respect, imaginings differ from desires, hopes, and other non-assertoric states, since in themselves, imaginings do not purport to represent the real world, either as it is, or as one would like it to be.

What still needs to be explained is how the proposed account applies to the refined thesis discussed above, namely, the thesis that B3 inclines John to believe its content only slightly or non-consciously. The problem is that if belief-like imaginings do not purport to represent what the real world is like, the perceptual experiences they penetrate should not generate any inclination, however slight, to believe their content. That is, if imaginatively-penetrated experiences do not purport to inform us about the real world, how can they incline imaginers to believe — even only slightly or non-consciously — that their content obtains in the real world? B3's degree of assertoricity, on our explanation, should be zero, whereas according to the refined thesis, B3 may be slightly assertoric.

This problem can be solved by recognizing that imaginings, despite being directed at an unreal world, sometimes generate a slight inclination to believe their content. Whatever the explanation for this phenomenon, it is a matter of everyday experience that, even if we are fully aware that we are imagining, and direct our mental states at some i-world, we sometimes find ourselves wondering whether what we are imagining is also true simpliciter. This phenomenon can occur in watching or reading fiction, modal reasoning, daydreaming, pretending, and any other context in which imaginings arise. Suppose you imagine, or take it to be true in the pertinent i-world (a movie's fictional world, the world of a daydream, a game of make-believe, 
etc.), that human-like aliens live among us, that Elvis is alive, that a monster lives in a nearby lake, etc. Though aware that you are imagining, you might start to wonder whether the imagined propositions are true simpliciter: your imaginings might generate a slight inclination to believe that aliens live among us, Elvis is alive, etc. This scenario is certainly conceivable: for reasons that warrant a separate discussion, you may wonder, at least for a moment, whether the propositions you take to be true in the i-world are also true simpliciter. The refined thesis can be understood along these lines. This does not, however, detract from our main point: imaginings are able to reduce, if not completely block, the assertoricity of the perceptual experiences they penetrate, by rendering these experiences directed at the world of the imaginative interlude.

Another objection might be that sometimes imaginings are assertoric, and $d o$ purport to provide information about the (real) world. Consider cases of extreme imaginative immersion. Suppose that a subject, being totally immersed in her imaginings, takes their content so seriously that, to the extent that they penetrate her perceptual experience, they do not block its assertoric force. As we mentioned apropos case $\mathrm{C}$, a spectator could be so raptly immersed in the play she is watching that she experiences its content - a shooting, a bleeding victim, a sunset on the beach - assertorically. Although being immersed to that degree would seem to amount to believing, ${ }^{9}$ let us suppose that such cases indeed involve assertoric imaginings, not beliefs. This is compatible with our account, since as just explained, belief-like imaginings may sometimes induce the imaginer to consider the veracity of their content. The paper's focus, however, is nonassertoric perceptual experiences, and its goal is to account for non-assertoricity in terms of

\footnotetext{
${ }^{9}$ Schellenberg (2013) argues that if the subject is sufficiently immersed in her imaginings, they "become" beliefs, since imaginings and beliefs exist on a continuum. Cf. Liao and Doggett (2014) and Chasid (2017, §5).
} 
imaginings. For this purpose, it suffices to assume that commonplace imaginings (i.e., not the 'extreme' imaginings of total imaginative immersion), are non-assertoric. We contend that these non-assertoric imaginings penetrate perceptual experiences, rendering them non-assertoric. In cases $\mathrm{A}, \mathrm{B}$, and $\mathrm{C}$, the imaginings that shape the non-assertoric experiences are themselves nonassertoric, that is, they are not the sort of imaginings adduced by opponents of our account as counterexamples. Moreover, given that we are not ordinarily inclined by our imaginings to believe their content — we ordinarily remain aware that they reflect the truth in an imaginary world - the phenomena that require further explanation are imaginative immersion and other cases where our imaginings incline us to believe their content.

This point also explains why our account is compatible with another type of alleged assertoricity associated with imaginings. It might be argued that, since we sometimes gain knowledge (i.e., knowledge about the real world) through imagining, imaginings are, in an important sense, assertoric with respect to the real-world truths that we learn from them. ${ }^{10}$ Yet it is not necessarily the case that we learn from imagining, and even when we do, this does not entail that the primary role of imaginings is to impart that which is true simpliciter. Here, too, what requires explanation is the fact that we sometimes do learn from imaginings. Our claim in this paper is that since Mary's and John's belief-like imaginings do not purport to impart knowledge of the real world, the perceptual experiences penetrated by these imaginings do not incline Mary and John to believe that the content of these experiences is true in the real world; penetration by imaginings renders them non-assertoric.

\footnotetext{
${ }^{10}$ Whether it is possible to learn from imagining is much debated; see Kind and Kung (2016). To address the current objection, we can accept the views on which knowledge can be gained through imagining.
} 
The limited scope of our explanation should be emphasized. We do not claim that nonassertoric perceptual experience is always explained by imaginative penetration. Imaginings can thwart or reduce perceptual assertoricity, but perhaps there are other factors that can also have that effect. Each case of perceptual non-assertoricity should be examined separately, to see whether it incorporates imaginings, and whether they are indeed thwarting assertoricity. Consider, e.g., the experience of a stick partly submerged in water, which represents the stick as bent. What explains the fact that, ordinarily, we are not inclined by this experience to believe that the stick is bent? Does robust defeating evidence, or familiarity with this illusion, suffice to thwart perceptual assertoricity? Perhaps, though as we saw, these factors don't suffice to thwart assertoricity in other cases. Indeed, in the case of the stick, too, these factors do not completely thwart assertoricity. For if we focus on the submerged part of the stick, and try to ascertain its precise location, our visual experience may have assertoric force with respect to that part of the stick: as hard as we try to ignore our experience of the submerged part's specific location (knowing that our experience of the stick is non-veridical), it may mislead us. Hence our experience of the submerged part's location may have assertoric force that is thwarted neither by familiarity and defeating evidence, nor by imaginings. What about the non-assertoricity of our experience of the stick as having the high-level property of being bent? As we saw in the case of visual fictions, imaginings can sometimes explain the non-assertoricity of high-level properties. Perhaps our awareness of the illusion prompts us to imagine that the stick is bent; this imagining then penetrates our experience, to the effect that it represents the high-level property of bentness, rendering this experience non-assertoric. 
This explanation raises several concerns, one of which is whether imaginings can arise without much awareness. These concerns, as well as the idea that the failure of perceptual assertoricity may be due to other factors, merit separate discussion.

\section{Conclusion}

We started out by describing perceptual assertoricity, then adduced cases where perceptual experience is non-assertoric, i.e., does not incline the subject to believe its content. After showing why certain experiences are best described as not, or only slightly, inclining the perceiving subject to believe their content, we accounted for the failure of full assertoricity by invoking belief-like imaginings. We argued that, just as beliefs can penetrate perceptual experience, belief-like (propositional; attitudinal) imaginings can likewise penetrate perceptual experience. When perceptual experience is penetrated by imaginings rather than beliefs, it does not incline the subject to believe its content, since like imaginings, imaginatively-penetrated experience does not purport to represent truths simpliciter, but only truths of the pertinent imaginary world.

Several issues related to the scope of imaginative penetration and non-assertoric experiences require further examination. First, although we addressed falsidical experiences, it seems plausible that experiences whose content is true can also be rendered non-assertoric by imaginings. Recall the Perky experiment, whose subjects were not inclined to believe that there was a yellow object in front of them, a result interpreted as ensuing from the fact that the subjects believed that they were visualizing a yellow object. However, since defeating beliefsin this case, the belief that one is visualizing and not perceiving — do not suffice to block 
assertoricity, there may be a better explanation for the non-assertoricity of the experiences Perky described. We suggest that these experiences were penetrated by belief-like imaginings: believing that they were visualizing, the participants imagined that there was a banana in front of them. This belief-like imagining influenced their experiential state, rendering it directed at an imaginary world; as such, it did not purport to represent truths simpliciter, and was thus nonassertoric.

Another question pertains to the scope of the similarity between imaginings and beliefs. Recall that our argument is partly motivated by the fact that imaginings tend to 'mimic' beliefs in functional respects. On the basis of this general similarity, we argued that if beliefs can influence experience, belief-like imaginings can do so as well. The functional similarity between beliefs and imaginings is, however, far from total. ${ }^{11}$ It is obviously not true that, if we replace a belief with an imagining that has the same content, we get the same relations to other mental states. A specific point that remains to be explored is the extent to which imaginings are similar to beliefs with respect to penetrating perceptual experience.

Alon Chasid, Department of Philosophy, Bar-Ilan University, Ramat-Gan, 5290002, Israel

Assaf Weksler, Department of Philosophy \& Psyphas Program in Psychology and Philosophy, University of Haifa, 199 Aba Khoushy Ave., Mt. Carmel, Haifa, 3498838, Israel

This research was supported by the Israel Science Foundation (grant No. 939/16; PI: Alon Chasid).

${ }^{11}$ Dissimilarities are adduced in, e.g., Liao and Doggett (2014, 262ff). 


\section{References}

Chasid, Alon (2016). "Imaginatively-Colored Perception: Walton on Pictorial Experience," Southern Journal of Philosophy 54 (1):27-47.

Chasid, Alon (2017). "Imaginative Content, Design-Assumptions and Immersion," Review of Philosophy and Psychology 8 (2):259-72.

Currie, Gregory and Ravenscroft, Ian (2002). Recreative Minds: Imagination in Philosophy and Psychology. Oxford: Oxford UP.

Deroy, Ophelia (2015). "Modularity of Perception," in Mohan Matthen (ed.), Oxford Handbook of Philosophy of Perception. New York: Oxford UP, 755-78.

Doggett, Tyler and Egan, Andy (2007). "Wanting Things You Don’t Want," Philosophers' Imprint 7 (9):1-17.

Doggett, Tyler and Egan, Andy (2012). "How We Feel About Terrible, Non-existent Mafiosi," Philosophy and Phenomenological Research 84 (2):277-306.

Gendler, Tamar (2003). "On the Relation between Pretense and Belief," in Matthew Kieran and Dominic Lopes (eds.), Imagination, Philosophy, and the Arts. London: Routledge, 125-41.

Gendler, Tamar (2013). “Imagination,” The Stanford Encyclopedia of Philosophy (Fall 2013 Edition), Edward N. Zalta (ed.), URL = <http://plato.stanford.edu/archives/fall2013/entries/imagination/>.

Ghijsen, Harmen (2014). "Phenomenalist Dogmatist Experientialism and the Distinctiveness Problem," Synthese 191 (7):1549-66.

Glüer, Kathrin (2009). "In Defence of a Doxastic Account of Experience," Mind and Language $24(3): 297-327$. 
Kind, Amy (2001). "Putting the Image Back in Imagination," Philosophy and Phenomenological Research 62:85-109.

Kind, Amy (2013). “The Heterogeneity of the Imagination,” Erkenntnis 78 (1):141-59.

Kind, Amy (2016). "Introduction," in Amy Kind (ed.), Routledge Handbook of Philosophy of Imagination. New York: Routledge, 1-11.

Kind, Amy and Kung, Peter (eds.) (2016). Knowledge Through Imagination. New York: Oxford UP.

Langland-Hassan, Peter (2012). "Pretense, Imagination, and Belief: the Single Attitude Theory," Philosophical Studies 159 (2):155-79.

Liao, Shen-yi and Doggett, Tyler (2014). “The Imagination Box,” Journal of Philosophy 111 (5):259-75.

Macpherson, Fiona (2012). "Cognitive Penetration of Colour Experience: Rethinking the Issue in Light of an Indirect Mechanism," Philosophy and Phenomenological Research 84:24-62.

Martin, Michael G. F. (2002). “The Transparency of Experience,” Mind and Language 4 (4):376-425.

Matthen, Mohan (2005). Seeing, Doing, and Knowing: A Philosophical Theory of Sense Perception. New York: Oxford UP.

Nichols, Shaun (2004). “Imagining and Believing: The Promise of a Single Code," Journal of Aesthetics and Art Criticism 62 (2):129-39.

Nichols, Shaun (2006a). "Introduction," in Shaun Nichols (ed.), The Architecture of the Imagination, New York: Oxford UP, 1-16.

Nichols, Shaun (2006b). “Just the Imagination: Why Imagining Doesn't Behave Like Believing," Mind and Language 21 (4):459-74. 
Nichols, Shaun and Stich, Stephen (2003). Mindreading: An Integrated Account of Pretence, Self-Awareness, and Understanding of Other Minds, Oxford: Oxford UP.

Peacocke, Christopher (1985). "Imagination, Experience, and Possibility: A Berkeleian View Defended," in John Foster and Howard Robinson (eds.), Essays on Berkeley. Oxford: Clarendon, 19-35.

Perky, C. W. (1910). “An Experimental Study of Imagination,” American Journal of Psychology 21:422-52.

Schellenberg, Susanna (2013). "Belief and Desire in Imagination and Immersion,” Journal of Philosophy 110 (9):497-517.

Siegel, Susanna (2010). The Contents of Visual Experience. New York: Oxford UP.

Siegel, Susanna (2012). “Cognitive Penetrability and Perceptual Justification,” Noûs 26 (2):20122.

Siegel, Susanna and Silins, Nicholas (2015). “The Epistemology of Perception,” in Mohan Matthen (ed.), Oxford Handbook of Philosophy of Perception. New York: Oxford UP.

Stokes, Dustin (2012). "Perceiving and Desiring: A New Look at the Cognitive Penetrability of Experience," Philosophical Studies 158:479-92.

Teng, Lu (2018). “Is Phenomenal Force Sufficient for Immediate Perceptual Justification?” Synthese 195 (2):637-56.

Van Leeuwen, Neil (2011). "Imagination is Where the Action is," Journal of Philosophy 108 (2):55-77.

Van Leeuwen, Neil (2013). “The Meanings of 'Imagine' Part I: Constructive Imagination,” Philosophy Compass 8 (3):220-30.

Walton, Kendall (1990). Mimesis as Make-Believe, Cambridge MA: Harvard UP. 
Walton, Kendall (2008). Marvelous Images, New York: Oxford UP.

Walton, Kendall (2015). In Other Shoes: Music, Metaphor, Empathy, Existence, New York: Oxford UP. 